\title{
Bacteriophage Inhibition in Staphylococci
}

\author{
By MARY A. BEARD AND PHYLLIS M. ROUNTREE \\ Fairfax Institute of Pathology, Royal Prince Alfred Hospital, Sydney, Australia
}

(Received 5 February 1965)

\begin{abstract}
SUMMARY
The inhibitory effect of high-titre preparations of phage $\mathbf{4 7}$ on certain strains of Staphylococcus aureus belonging to phage group III was produced with a phage: cell ratio of approximately $1: 1$. Staphylococci showing inhibition by preparations of phage 47 were converted to phage sensitivity by lysogenization with a phage derived from a strain sensitive to phage 47 . Multiplication of phage $\mathbf{4 r}$ in lysogenized clones was compared with that in the original inhibited strains. This showed that inhibition was due to a phage/cell interaction in which most of the infected cocci were killed; a minority produced a few phage particles in smaller numbers with a longer latent period.
\end{abstract}

\section{INTRODUCTION}

In 1952 Williams \& Rippon described the 'inhibitory' effect which may follow the application of undiluted high-titre phage preparations to certain strains of Staphylococcus aureus. The appearance produced on nutrient agar plates is a thinning of bacterial growth in the area on which the phage has been deposited, rather than the complete clearing seen with a phage-sensitive culture. When such a phage preparation is titrated out this 'inhibition' disappears, but no single plaques can be observed in the higher dilutions. Williams \& Rippon stated that phage preparations from which the phage had been removed by absorption to heat-killed cocci, by filtration or by neutralization with antisera, no longer gave the effect. They concluded that the inhibitory agent could act only in the presence of phage. That the occurrence of inhibition might be influenced by the lysogenic state of the staphylococcus was indicated by the observations of Rountree (1959) and Rountree \& Asheshov (1961) on staphylococci of phage type 80/81. These strains showed inhibition with phages 52 and $52 \mathrm{~A}$ but could be converted to full sensitivity to these phages as a result of prophage substitution. The present paper reports observations on staphylococci of phage group III which show inhibition with phage 47 . The observations indicate that the appearance of inhibition on nutrient agar is due to a phage/cell interaction, in which the majority of infected cocci are killed and only a minority produce new phage particles.

\section{METHODS}

Staphylococci. The strains of Staphylococcus aureus used were isolated from patients in this hospital; their phage reactions are shown in Table 1. Strain 009 was lysed by typing phage 47 at 1000 times its routine test dilution (RTD), but strains 2, 676 and 8503 showed inhibition. Clones, lysogenized with a serological type B phage (phage $009^{\prime}$ ) from strain 009, were prepared. Strains 2, 676 and 8503 were lysogenic and carried other serological type B phages. 
Phage stocks. Phage 47 stocks were propagated on staphylococcus propagating strain (PS) 47 in broth (Blair \& Williams, 1961). Phage 009' was prepared by ultraviolet induction of strain 009 . Cocci grown in veal broth were centrifuged, washed and resuspended in Monod's buffer (1951) and then irradiated under a Westinghouse Sterilamp at a distance of $36 \mathrm{~cm}$. for $30 \mathrm{sec}$; they were then transferred to fresh broth, incubated at $37^{\circ}$ for $1 \mathrm{hr}$ and placed at room temperature until clearing occurred. Phages were filtered through Gradocol membranes of $800 \mu \mu$ APD and tested for sterility before use.

Table 1. Phage reactions of strains of Staphylococcus aureus used in the inhibition studies

\begin{tabular}{cccccc}
\multicolumn{5}{c}{ Reaction with phages } \\
\cline { 2 - 6 } Staphylococcus & 47 & $\begin{array}{c}53 \\
\text { at RTD } \times 1000^{*}\end{array}$ & 75 & $\begin{array}{c}\mathbf{5 0 9} \\
\text { at RTD }\end{array}$ \\
$\mathbf{0 0 9}$ & + & + & () & + & - \\
$\mathbf{2}$ & $(+)$ & + & () & () & + \\
$\mathbf{6 7 6}$ & () & + & () & () & + \\
$\mathbf{8 5 0 3}$ & () & + & () & () & + \\
$\mathbf{2}\left(009^{\prime}\right)$ & + & + & () & + & - \\
$\mathbf{6 7 6}\left(009^{\prime}\right)$ & + & + & () & + & - \\
$\mathbf{8 5 0 3}\left(009^{\prime}\right)$ & () & + & () & () & -
\end{tabular}

* RTD = Routine Test Dilution.

$+=$ confluent lysis; ()$=$ inhibition; $(+)=$ inhibition with scattered plaques; $-=$ no reaction.

Lysogenization. Staphylococcal strains were lysogenized by spotting undiluted phage onto a lawn of cocci. After incubation, a small quantity of the secondary bacterial growth in the area of lysis was streaked on blood agar plates. Single colonies were picked into broth and tested for the presence of the lysogenizing phage, for resistance to it and for alteration in phage-typing pattern. The lysogenized strains are numbered in the usual way, e.g. $2\left(009^{\prime}\right)$ indicated strain 2 lysogenized with phage from strain 009.

Titration of inhibition. To determine the highest dilution of a phage preparation capable of giving inhibition on nutrient agar, tenfold dilutions were made in broth and quantities of $\mathbf{0 . 0 1} \mathrm{ml}$. were spotted onto the surface of phage agar plates previously flooded with a $4 \mathrm{hr}$ broth culture of a strain known to give inhibition. The plates were incubated overnight at $30^{\circ}$. Care was required in the preparation of the agar plates and their flooding with the bacterial culture since variations in the depth of agar and the thickness of the bacterial lawn influenced the ease with which the end point of inhibition could be read. When the approximate titre of inhibition had been obtained, more closely spaced dilutions were tested similarly.

\section{RESULTS}

\section{Relationship of phage titre to inhibition titre}

Three stocks of phage 47 were examined to see what correspondence there was between the number of infective particles determined by plating on staphylococcus PS 47 and the highest dilution of the preparation that would produce inhibition on strain 8503. After titration on strains PS 47 and 8503 the stocks were centrifuged 
in a Spinco Model $\mathrm{L}$ centrifuge at $20,000 \mathrm{rev} / \mathrm{min}$. for $60 \mathrm{~min}$. The supernatant fluids were removed and the pellets resuspended in one tenth the original volume of broth and titrated. If it is the phage particles or some substance associated with them that produces inhibition there should be correspondence between the titres. The results (Table 2) indicate fair correspondence, tenfold concentration of the phage producing a tenfold increase in the inhibition titre. The highest dilutions of phage giving inhibition contained from $2.5 \times 10^{5}$ to $1.8 \times 10^{6}$ phage particles/ $0.01 \mathrm{ml}$.

Table 2. Relationship of titre of phage 47 on staphylococcal strain PS 47 to inhibition titre on strain 8503

\begin{tabular}{|c|c|c|c|}
\hline Phage preparation & $\begin{array}{l}\text { Titre of phage } \\
\text { on strain PS } 47 \\
\text { (particles } / \mathrm{ml} . \text { ) }\end{array}$ & $\begin{array}{l}\text { Inhibition } \\
\text { titre/ml. on } \\
\text { strain } 8503\end{array}$ & $\begin{array}{c}\text { Minimum } \\
\text { number } \\
\text { of phage } \\
\text { particles } / 0 \cdot 01 \mathrm{ml} \text {. } \\
\text { which produce } \\
\text { inhibition }\end{array}$ \\
\hline $\begin{array}{c}\text { Stock } 1 \text { (a) Before centrifugation } \\
\text { (b) Precipitate after } \\
\text { centrifugation }\end{array}$ & $\begin{array}{l}8.6 \times 10^{9} \\
8.6 \times 10^{10}\end{array}$ & $\begin{array}{l}1 / 100 \\
1 / 1600\end{array}$ & $\begin{array}{l}8 \cdot 6 \times 10^{5} \\
5 \cdot 5 \times 10^{5}\end{array}$ \\
\hline (c) Supernatant fluid & $1 \cdot 1 \times 10^{9}$ & $1 / 20$ & $5.5 \times 10^{5}$ \\
\hline $\begin{array}{l}\text { Stock } 2 \text { (a) Before centrifugation } \\
\text { (b) Precipitate after } \\
\text { centrifugation }\end{array}$ & $\begin{array}{l}6.9 \times 10^{9} \\
8 \cdot 0 \times 10^{10}\end{array}$ & $\begin{array}{l}1 / 80 \\
1 / 1000\end{array}$ & $\begin{array}{l}8.6 \times 10^{5} \\
8 \cdot 0 \times 10^{5}\end{array}$ \\
\hline $\begin{array}{l}\text { (c) Supernatant nula } \\
\text { Stock } 3 \text { (a) Before centrifugation }\end{array}$ & $\begin{array}{l}1.8 \times 10^{\circ} \\
6.5 \times 10^{9}\end{array}$ & $1 / 10$ & $\begin{array}{l}1.8 \times 10^{6} \\
4.0 \times 10^{5}\end{array}$ \\
\hline $\begin{array}{l}\text { (b) Precipitate after } \\
\text { centrifugation } \\
\text { (c) Supernatant fluid }\end{array}$ & $\begin{array}{l}6.5 \times 10^{6} \\
2.5 \times 10^{10} \\
1.6 \times 10^{9}\end{array}$ & $\begin{array}{l}1 / 160 \\
1 / 1000\end{array}$ & $\begin{array}{l}4.0 \times 10^{3} \\
2.5 \times 10^{5}\end{array}$ \\
\hline
\end{tabular}

Estimates were made of the numbers of cocci present on the agar plate at the time when the inhibitory phage preparation was deposited. An inoculum of $0.45 \mathrm{ml}$. of a $5 \mathrm{hr}$ broth culture of strain 8503 was flooded onto an agar plate and a measured surplus of $0.1 \mathrm{ml}$. removed, leaving an inoculum of $0.35 \mathrm{ml}$. A colony count of the broth culture was made immediately before flooding. $0.01 \mathrm{ml}$. volumes of phage were deposited on the inoculated and dried plates. After incubation the diameters of 40 zones of inhibition were measured. From these, the mean area of the zones was calculated: it was one-thirtyseventh of the area of the plate. The approximate number of cocci within the area of the phage drop was calculated from these zone measurements and from the cell count. With an inoculum of $2 \cdot 6 \times 10^{6}$ cocci/zone, a phage: cell ratio of approximately $1: 1$ was sufficient to produce inhibition. There was thus no evidence that inhibition was due to lysis-from-without as a result of multiple infection.

\section{Change from inhibition to phage sensitivity}

Staphylococcus strain 009 which was sensitive to lysis by phages 47 and 75 carried a prophage. When strains 2 and 676 were lysogenized by phage $009^{\prime}$ they too became fully sensitive to phages 47 and 75 , suggesting that the prophage state of the cocci might determine whether they showed lysis or inhibition (see Table 1 ). Plate 1 shows the appearances of the titrations of phages 47 and 75 on strain 676 before and after its conversion to phage sensitivity. On the other hand, strain 8503, when lysogenized with phage $009^{\prime}$ remained inhibited by phages 47 and 75 . 
The lysogenized clones of strains 2 and 676 still retained their original prophages, indicating that the mechanism of this conversion was not an obvious prophage substitution. Further evidence of the influence of phage $009^{\prime}$ on the phenomenon of inhibition was obtained by curing strain $2\left(009^{\prime}\right)$ of prophage $009^{\prime}$. After ultraviolet irradiation of strain $2\left(009^{\prime}\right)$ on citrate agar and replication of the surviving colonies on plates flooded with strain 2 , one non-lysogenic colony was found among 900 lysogenics. On retesting with phage 47 this clone was inhibited.

It was concluded that at least in some cocci prophage $009^{\prime}$ acted as a genetic factor determining the phenotypic response to infection with phage 47 . When this prophage was present in the cocci, infection of them with phage 47 resulted in lysis; in its absence they were inhibited by phage 47 .

\section{Phage replication in sensitive and in inhibited strains}

Advantage was taken of the conversion of the strains 2 and 676 to phage sensitivity to compare the multiplication of phage 47 in these strains with that in the original inhibited strains and in strain 8503. Where appropriate, multiplication of phage 47 in strain PS 47 was used as a control.

Table 3. Percentage adsorptions and adsorption rates of phage 47 on various strains of Staphylococcus

\begin{tabular}{|c|c|c|c|c|c|c|c|}
\hline \multirow{2}{*}{$\begin{array}{l}\text { Staphylococcus } \\
\text { strain }\end{array}$} & \multirow{2}{*}{$\begin{array}{c}\text { Action of } \\
\text { phage } 47 \\
\text { at } \mathrm{RTD} \times \mathbf{1 0 0 0}\end{array}$} & \multicolumn{3}{|c|}{ Phage adsorbed at } & \multicolumn{3}{|c|}{ Adsorption rate at } \\
\hline & & 2 min. & $\begin{array}{l}5 \text { min. } \\
\text { adsork }\end{array}$ & $10 \mathrm{~min}$ & 2 min. & $\begin{array}{c}5 \mathrm{~min} . \\
0^{-9} \mathrm{ml} .\end{array}$ & $\begin{array}{l}10 \mathrm{~min} . \\
\text { ain.) }\end{array}$ \\
\hline 8503 & Inhibition & $57 \cdot 0$ & $76 \cdot 0$ & $90 \cdot 0$ & $3 \cdot 7$ & $2 \cdot 6$ & $2 \cdot 1$ \\
\hline 2 & Inhibition & $31 \cdot 0$ & $49 \cdot 0$ & $75 \cdot 0$ & $1 \cdot 9$ & $1 \cdot 5$ & 1.5 \\
\hline 676 & Inhibition & $66 \cdot 0$ & $80 \cdot 0$ & $93 \cdot 0$ & $4 \cdot 3$ & $\mathbf{2} \cdot \mathbf{5}$ & $\mathbf{2} \cdot \mathbf{1}$ \\
\hline $2\left(009^{\prime}\right)$ & Lysis & $46 \cdot 0$ & $59 \cdot 0$ & $77 \cdot 0$ & $\mathbf{3} \cdot \mathbf{3}$ & 1.9 & $1 \cdot 6$ \\
\hline $676\left(009^{\prime}\right)$ & Lysis & $68 \cdot 0$ & $84 \cdot 0$ & 93.0 & $4 \cdot 4$ & $2 \cdot 8$ & $2 \cdot 0$ \\
\hline $\operatorname{PS} 47$ & Lysis & $39 \cdot 0$ & $60 \cdot 0$ & $71 \cdot 0$ & $\mathbf{2 \cdot 0}$ & $\mathbf{1} \cdot \mathbf{5}$ & $1 \cdot 0$ \\
\hline
\end{tabular}

Adsorption rates. Rates of adsorption of phage $\mathbf{4 7}$ to its own propagating strain, to strains showing inhibition and to the lysogenized clones were determined. A broth culture was grown at $37^{\circ}$ with aeration until the concentration was $1 \times 10^{8}$ cocci/ml. One ml. of the culture was mixed with $1 \mathrm{ml}$. of phage 47 (titre $1 \times 10^{8}$ particles $/ \mathrm{ml}$.) and $0.01 \mathrm{ml} .1 \%(\mathrm{w} / \mathrm{v}) \mathrm{CaCl}_{2}$, both previously warmed to $37^{\circ}$, and the mixture held at $37^{\circ}$. At 2, 5 and $10 \mathrm{~min}$. after mixing, $0.1 \mathrm{ml}$. samples were taken, diluted immediately to 1/100 in broth and cooled in an ice water bath. After centrifugation the numbers of phage particles in the supernatant fluids were assayed and the adsorption rate $\mathbf{K}$ was calculated. There were minor differences in the behaviour of the strains (Table 3), strains $676,676\left(009^{\prime}\right)$ and 8503 adsorbing the phage at a faster rate than did PS 47 and strains 2 and $2\left(009^{\prime}\right)$. Lysogenization with phage $009^{\prime}$ had no effect on the adsorption rates in strains 2 and 676 . It was concluded that inhibition did not involve processes concerned with the initial steps of phage infection and was not due, for example, to a deficiency of appropriate phage receptors on the surface of the cocci.

Recovery of adsorbed phage from inhibited cocci. The proportions of adsorbed phage 
recoverable from the cocci as infective centres during the latent period were determined. Using the samples taken at $10 \mathrm{~min}$. in the previous experiment, the centrifuge-deposited cocci were resuspended in $0.5 \mathrm{ml}$. broth and the number of infective centres assayed by plating $0.01 \mathrm{ml}$. volumes on strain Ps 47. A smaller percentage of the adsorbed phage was recovered from the strains showing inhibition than from the phage-sensitive strains (Table 4). In strains 8503 and 676 , only 16 and $14 \%$ respectively of the adsorbed phage registered as infective centres as compared with $37 \%$ in $676\left(009^{\prime}\right)$ and $63 \%$ in strain PS 47 . Strain 2 differed from the other inhibited strains in that $30 \%$ of the adsorbed phage was recoverable and that lysogenization with phage $009^{\prime}$ only increased this to $36 \%$, an insignificant difference. It should be noted that this strain 2 occasionally showed evidence of partial sensitivity to phage $\mathbf{4 7}$ in that very minute plaques were sometimes seen in higher phage dilutions on nutrient agar.

Table 4. The recovery of adsorbed phage from staphylococci infected with phage 47

\begin{tabular}{|c|c|c|c|c|c|c|}
\hline Staphylococcus & $\begin{array}{l}\text { Action of phage } 47 \\
\text { at RTD } \times 1000\end{array}$ & $\begin{array}{c}\text { Phage added } \\
\left(\times 10^{6} / \mathrm{ml} .\right) \\
(a)\end{array}$ & $\begin{array}{c}\text { Phage } \\
\text { in super- } \\
\text { natant } \\
\text { fluid } \\
\left(\times 10^{6} / \mathrm{ml} .\right) \\
(b)\end{array}$ & $\begin{array}{c}\text { Phage } \\
\text { adsorbed } \\
\left(\times 10^{8} / \mathrm{ml} .\right) \\
(a-b)\end{array}$ & $\begin{array}{c}\text { Phage } \\
\text { recovered } \\
\text { as } \\
\text { infective } \\
\text { centres } \\
\left(\times 10^{8} / \mathrm{ml} .\right)\end{array}$ & $\begin{array}{c}\text { Adsorbed } \\
\text { phage } \\
\text { recovered } \\
(\%)\end{array}$ \\
\hline 8503 & Inhibition & 130 & 12 & 118 & 19 & 16 \\
\hline 2 & Inhibition & 100 & 25 & 75 & 23 & 30 \\
\hline 676 & Inhibition & 150 & 10 & 140 & 20 & 14 \\
\hline $2\left(009^{\prime}\right)$ & Lysis & 130 & 30 & 100 & 36 & 36 \\
\hline $676\left(009^{\prime}\right)$ & Lysis & 140 & 9 & 131 & 48 & 37 \\
\hline Ps 47 & Lysis & 100 & 29 & 71 & 45 & 63 \\
\hline
\end{tabular}

Death of infected cocci within the inhibition zone on nutrient agar

To determine how many inhibited cocci were killed when infection took place on nutrient agar, the numbers of viable cocci within the zone of inhibition were assayed at $30 \mathrm{~min}$. intervals up to $4 \mathrm{hr}$ after the addition of the phage. The number of viable cocci from an uninfected area of the plate was also determined at the same time. An agar plate was inoculated with $0.35 \mathrm{ml}$. of broth culture containing $2.5 \times 10^{8} \mathrm{cocci} / \mathrm{ml}$. and dried. Drops $(0.01 \mathrm{ml}$.) of undiluted phage 47 were deposited on the plate and allowed to dry. By using a sterile test-tube a circle of agar $8 \mathrm{~mm}$. in diam. was punched out of the inoculated plate from within the area of the phage drop. A similar sample was taken from outside the area of phage infection. Each sample was placed in $1 \mathrm{ml} .0 \cdot 85 \%$ (w/v) NaCl, shaken 30 times, diluted, and $0.01 \mathrm{ml}$. volumes plated in quadruplicate on agar plates, the inocula being spread with a glass rod. After overnight incubation at $37^{\circ}, 95 \%$ of the calculated inoculum of an uninfected sample could be recovered by this method. The results (Figs. 1-4) showed normal growth curves for all uninoculated cultures. The colony count decreased continuously in strains $2\left(009^{\prime}\right), 676\left(009^{\prime}\right)$ and PS 57 after infection with phage 47 . The inhibited strains showed a temporary decrease in the colony count within 60-90 min of infection, after which the numbers of cocci increased at rates similar to the growth rate of the uninfected cocci. The 'secondary growth' of inhibited strains was not due to selection of pre-existing phage-resistant mutants or to the presence of lysogenized cocci, since surviving cocci cultivated from the zone 


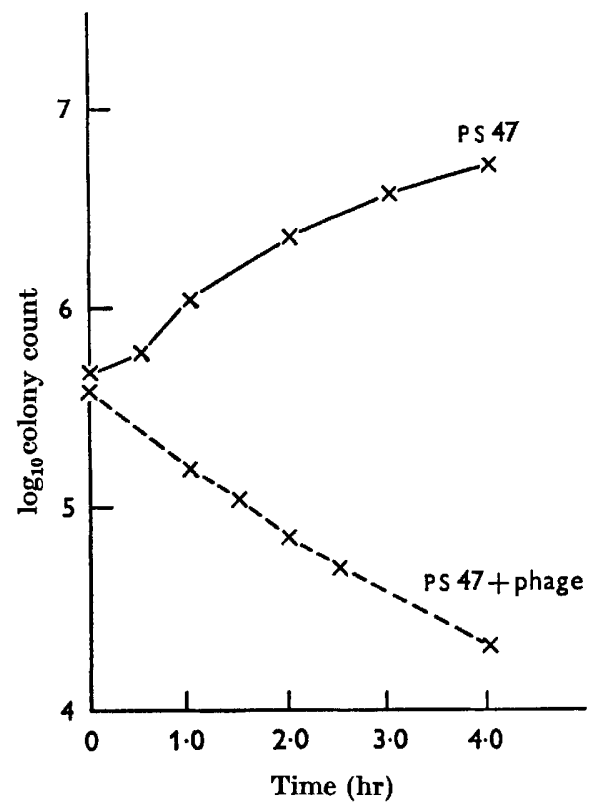

Fig. 1

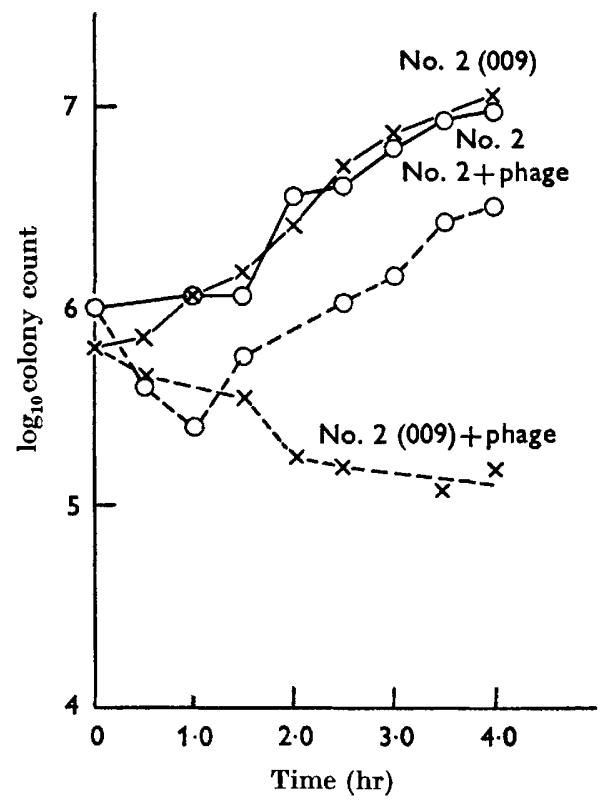

Fig. 3

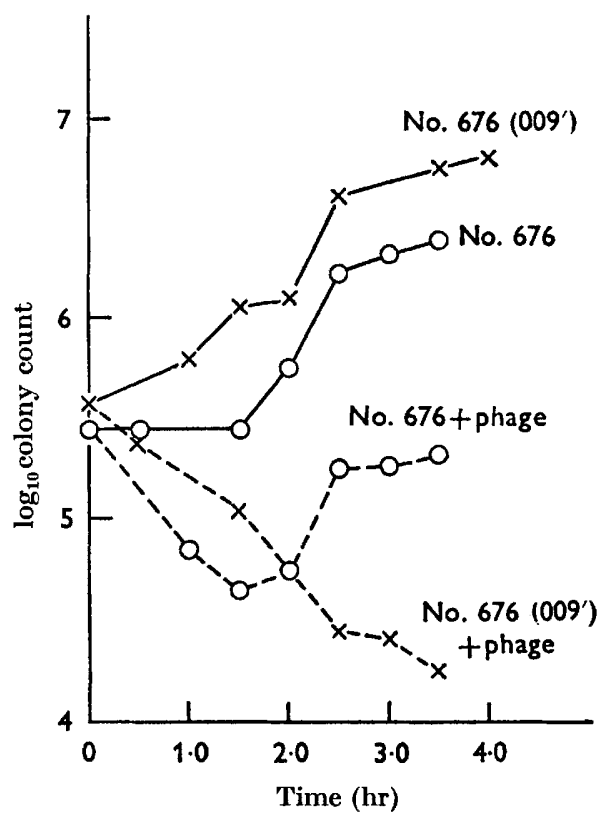

Fig. 2

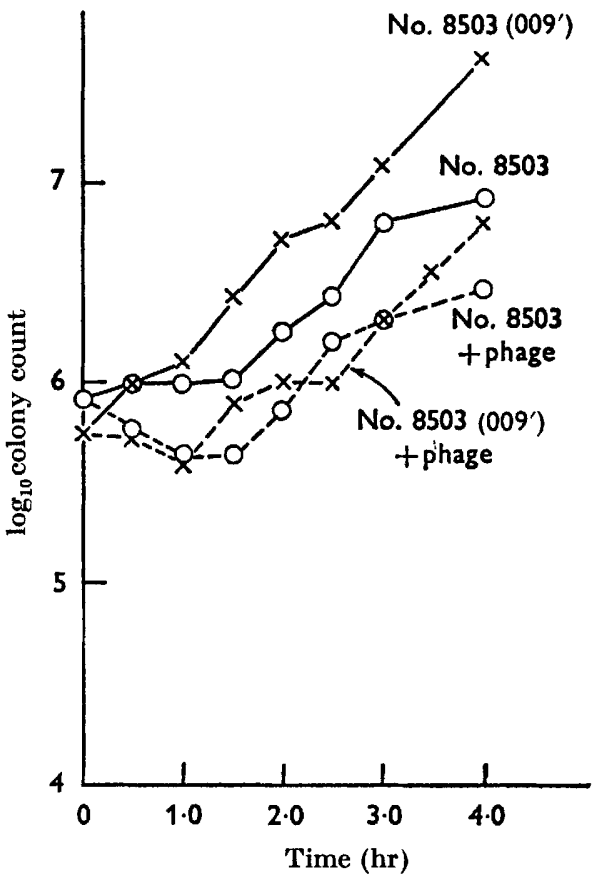

Fig. 4

Figs. 1-4. Colony counts of staphylococeal strains following infection with phage 47 on nutrient agar. $\mathrm{O}--\mathrm{O}, \times---\times$, cocci infected with phage 47 ; $0-\mathrm{O}$, $x-x$, uninfected cocci.

Fig. 1. Staphylococcus strain PS47.

Fig. 2. Strains 676 and $676\left(009^{\prime}\right)$.
Fig. 3. Strains 2 and $2\left(009^{\prime}\right)$.

Fig. 4. Strains 8503 and $8503\left(009^{\prime}\right)$. 


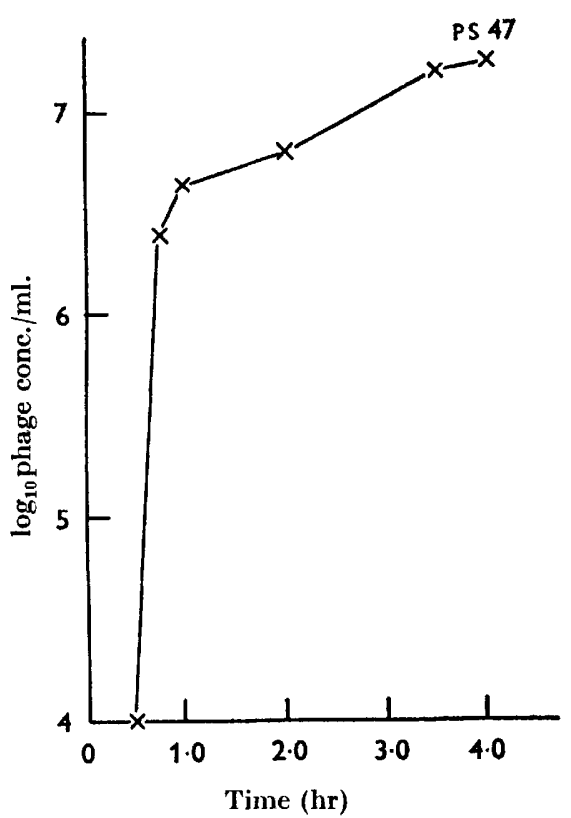

Fig. 5

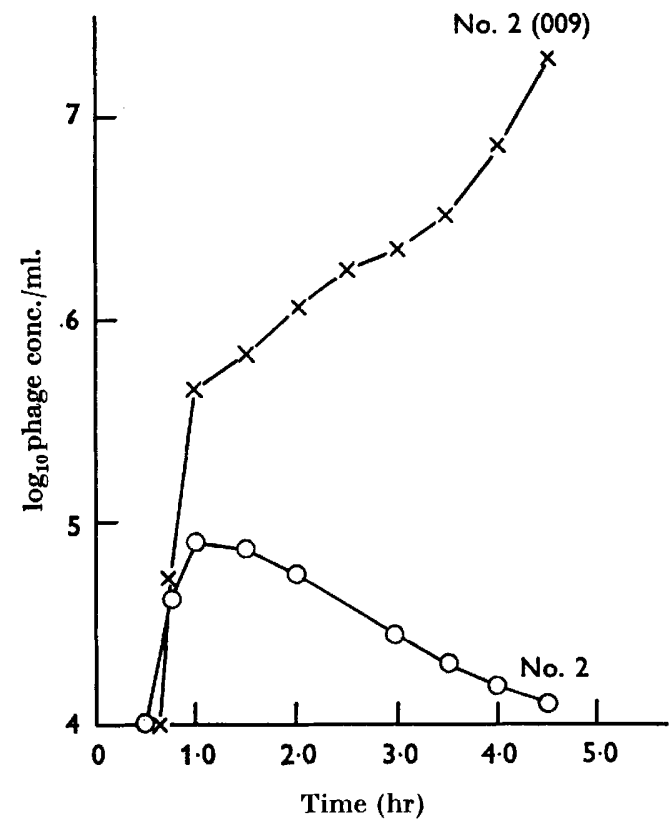

Fig. 7

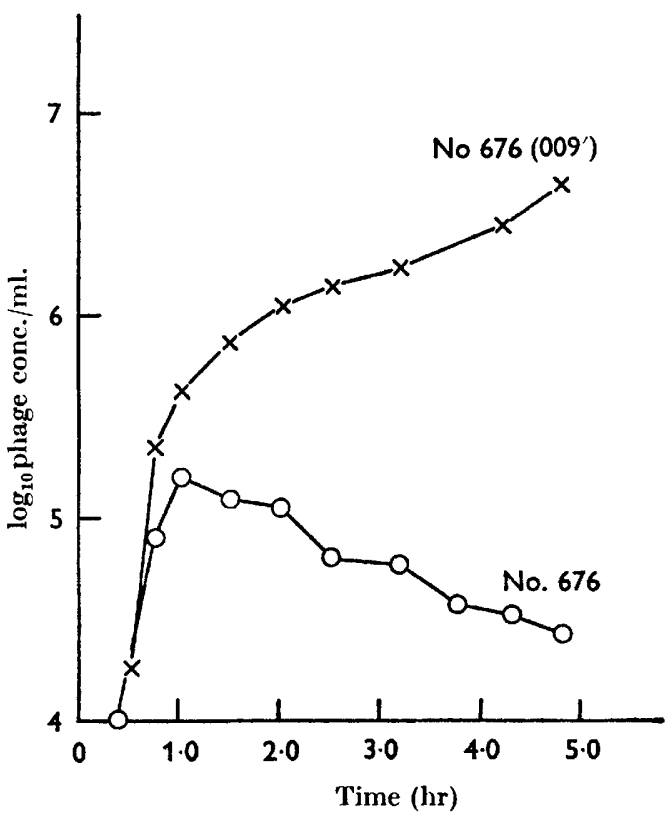

Fig. 6

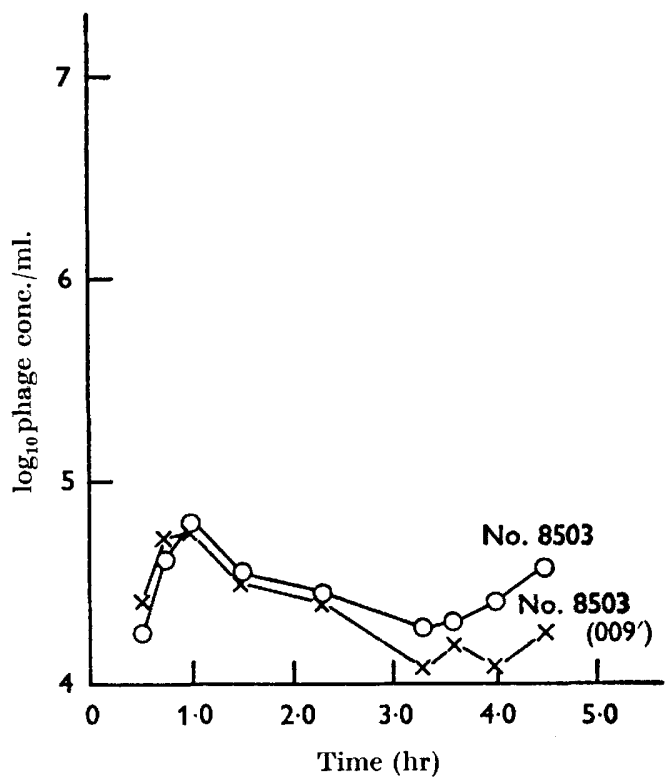

Fig. 8

Figs. 5-8. Production of phage 47 by strains of staphylococei grown in broth.

Fig. 5. Strain Ps 47 .

Fig. 6. Strains 676 and $676\left(009^{\prime}\right)$.

Fig. 7. Strains 2 and $2\left(009^{\prime}\right)$.

Fig. 8. Strains 8503 and $8503\left(009^{\prime}\right)$. 
of inhibition still showed inhibition when retested with phage 47. It was concluded that death of cocci within 60-90 min. of infection was in part responsible for the appearance of inhibition on agar plates. In the fully sensitive cultures PS 47, $2\left(009^{\prime}\right)$ and $676\left(009^{\prime}\right)$ the death of cocci continued throughout the period of observation, ultimately producing clear zones of lysis.

\section{Phage production by inhibited strains}

The production of phage 47 by sensitive, inhibited and converted staphylococcal strains was examined in broth. A broth culture was grown at $37^{\circ}$ with aeration to a concentration of $2.0 \times 10^{8} \mathrm{cocci} / \mathrm{ml}$., $1 \mathrm{ml}$. of phage 47 was added to $1 \mathrm{ml}$. of culture to give a ratio of 3 to 4 phage particles/coccus. After $20 \mathrm{~min}$. adsorption at $37^{\circ}$ the mixture was cooled, centrifuged and the cocci resuspended in $2 \mathrm{ml}$. broth. Unadsorbed phage was neutralized by mixing the cocci suspension with antiserum and

Table 5. The individual burst sizes of phage 47 in cells of

\begin{tabular}{|c|c|c|c|c|c|c|c|c|c|c|c|c|c|c|}
\hline \multirow{2}{*}{$\begin{array}{r}\text { Staphy- } \\
\text { lococcus } \\
\mathbf{2}\end{array}$} & \multirow{2}{*}{$\begin{array}{c}\text { Number } \\
\text { of } \\
\text { samples } \\
200\end{array}$} & \multirow{2}{*}{$\begin{array}{c}\text { Number } \\
\text { of } \\
\text { plates } \\
\text { with no } \\
\text { plaques } \\
162\end{array}$} & \multirow{2}{*}{$\begin{array}{c}\begin{array}{c}\text { Number } \\
\text { of } \\
\text { plates }\end{array} \\
\mathbf{3 8}\end{array}$} & \multicolumn{11}{|c|}{ Plates with plaques } \\
\hline & & & & $\begin{array}{l}\text { Total } \\
\text { plaques }\end{array}$ & & & & & Plaq & jues & 3/plat & & & \\
\hline & & & & 164 & $\begin{array}{l}1 \\
1 \\
1 \\
1 \\
1 \\
1\end{array}$ & $\begin{array}{l}1 \\
1 \\
1 \\
1 \\
1 \\
1 \\
1\end{array}$ & $\begin{array}{l}1 \\
1 \\
1 \\
1 \\
1 \\
1\end{array}$ & $\begin{array}{l}2 \\
2 \\
2 \\
2 \\
2 \\
2\end{array}$ & $\begin{array}{l}\mathbf{3} \\
\mathbf{3} \\
\mathbf{3}\end{array}$ & $\begin{array}{l}4 \\
4\end{array}$ & $\mathbf{5}$ & 6 & 78 & $\begin{array}{l}9 \quad 2232 \\
\quad 29\end{array}$ \\
\hline $2\left(009^{\prime}\right)$ & 120 & 72 & 48 & 1412 & $\begin{array}{l}1 \\
1 \\
1 \\
1 \\
1\end{array}$ & $\begin{array}{l}1 \\
1 \\
1 \\
1 \\
1\end{array}$ & $\begin{array}{l}2 \\
2 \\
3 \\
3\end{array}$ & $\begin{array}{ll}4 & 1 \\
5 & 18 \\
7 & 18 \\
18 \\
1 \\
18\end{array}$ & $\begin{array}{l}21 \\
21 \\
21 \\
21 \\
21 \\
22 \\
24 \\
27 \\
27\end{array}$ & $\begin{array}{l}40 \\
44 \\
47 \\
48 \\
48 \\
52 \\
53 \\
58\end{array}$ & $\begin{array}{l}66 \\
68 \\
69 \\
\end{array}$ & $\begin{array}{ll}75 & 8 \\
76 & 8\end{array}$ & $\begin{array}{ll}80 & 92 \\
84\end{array}$ & 2112 \\
\hline 676 & 120 & 103 & 17 & 106 & $\begin{array}{l}1 \\
1 \\
1 \\
1\end{array}$ & $\begin{array}{l}1 \\
1 \\
1 \\
1\end{array}$ & $\begin{array}{l}\mathbf{3} \\
\mathbf{3}\end{array}$ & 4 & 79 & $\begin{array}{l}12 \\
13 \\
15\end{array}$ & & & & \\
\hline $676\left(009^{\prime}\right)$ & 110 & 83 & 27 & 683 & $\begin{array}{l}\mathbf{1} \\
\mathbf{2} \\
\mathbf{2} \\
\mathbf{2}\end{array}$ & $\begin{array}{l}\mathbf{3} \\
\mathbf{3} \\
\mathbf{3}\end{array}$ & $\begin{array}{ll}5 & 1 \\
6 & 1 \\
& 1 \\
1 \\
1 \\
1 \\
& 1\end{array}$ & $\begin{array}{ll}0 & 2 \\
2 & 2 \\
3 & 2 \\
6 & 2 \\
7 & 2 \\
8 & \end{array}$ & $\begin{array}{l}34 \\
39 \\
9\end{array}$ & $\begin{array}{l}45 \\
46\end{array}$ & 57 & & 8199 & \\
\hline
\end{tabular}

holding at $37^{\circ}$ for $10 \mathrm{~min}$. A final dilution of $1 / 100$ was made in broth, kept at $37^{\circ}$ and $0.5 \mathrm{ml}$. samples taken at $30 \mathrm{~min}$. intervals. After cooling and centrifugation, the numbers of phage particles in the supernatant fluid (that is, the numbers of new particles released) were counted.

Staphylococcal strain PS 47 and the converted strains $2\left(009^{\prime}\right)$ and $676\left(009^{\prime}\right)$ gave high yields of phage (Figs. 5-8), there being increases of $3 \mathrm{log}$ value after 4-5 hr. The inhibited strains, 2, 676 and 8503 showed an increase in the phage counts of one log or less between 40 and $60 \mathrm{~min}$. Thereafter, there was a gradual decrease in 
the counts which might be explained by the neutralizing action of the low concentration of antiserum still present in the diluted growth tubes. Except in the 8503 strains there was no evidence of further phage multiplication after the first burst.

The yield of phage 47 by individual cocci was determined in the inhibited strains 2 and 676 and in the converted strains $2\left(009^{\prime}\right)$ and $676\left(009^{\prime}\right)$. After infection and neutralization by antisera, the infected cocci were diluted in broth to give less than one coccus $/ 0.01 \mathrm{ml}$. (at this dilution no effective antiserum should remain); $0.01 \mathrm{ml}$. samples were then distributed into separate tubes, held at $37^{\circ}$ for $50 \mathrm{~min}$. and the whole of each sample plated on strain PS 47. Table 5 shows the wide range of plaque counts observed. Those tubes giving one plaque were considered to have each contained an infected coccus whose burst was delayed until after the contents had been plated on strain PS 47. The average burst size was calculated from these data; for strains 2 and 676 plates showing one plaque were excluded; for strains $2\left(009^{\prime}\right)$ and $676\left(009^{\prime}\right)$ counts of three or less were excluded. The average burst sizes were greater in the converted strains than in the original strains; in strain $2\left(009^{\prime}\right)$ it was 33.9 compared with 8.3 in strain 2 , and in $676\left(009^{\prime}\right) 30.3$ compared with 12.2 in strain 676.

\section{DISCUSSION}

The behaviour of the inhibited strains of Staphylococcus examined in the present work provided evidence that the phenomenon of inhibition seen in phage typing is essentially a phage/cell interaction. A comparison of the behaviour of inhibited strains and their sensitive derivatives during the various steps of the phage cycle enabled some conclusions to be drawn as to the step or steps in the cycle at which inhibition operates. A ratio of approximately one infective particle to each coccus was sufficient to produce inhibition on nutrient agar, thus disposing of the hypothesis that lysis-from-without might be responsible for the appearance of inhibited cultures. Both inhibited and sensitive cocci adsorbed phage $\mathbf{4 7}$ at comparable rates, and about the same proportions of cocci were killed in the first round of infection. Thereafter, divergence in behaviour was observed. On nutrient agar plates showing inhibition, growth of the surviving cocci occurred, whereas on plates giving areas of lysis, the colony count of staphylococci decreased steadily, presumably as the result of the infection of cocci which had escaped the first round of infection. Phage growth curves in broth indicated that only a proportion of the infected cocci of the inhibited strains was able to produce infective particles, that the average yield from these productive cocci was lower than that from fully sensitive cocci and that lysis of some of these productive cocci was delayed. In other words, inhibition was not due to prophage immunity in which the multiplication of homologous infecting phage is completely blocked but to a partial incompetence of the cocci to produce infective phage. At what stage in the latent period this incompetence is expressed cannot be stated from the available data. That the infected cocci are no longer viable and that a proportion can produce complete phage although in decreased amount suggests a defect in maturation of the phage and/or in the production of an enzyme concerned in phage release. Study of infected cocci lysed by cyanide during the latter part of the latent period might provide information on these points.

When these facts are considered, an explanation of the appearance of inhibition on solid media is apparent. The number of cocci in initial contact with phage when 
it is spotted on a nutrient agar plate is limited. When a phage preparation is used which contains sufficient infective particles theoretically to infect every coccus, 60 to $90 \%$ of the cocci are killed but only 15 to $30 \%$ produce fewer new particles, and some belatedly. The chances, then that these new particles may cause a second round of infection in cocci which are alive and growing, are small; they are more likely to encounter cocci that have been killed while many of the growing cocci that they do infect will be unable to make phage. In the cocci which survive initial infection growth and division occurs as in uninfected cocci. The final result is a bacterial zone of decreased density. When diluted phage is applied to such incompetent cocci in numbers such that there is one particle to every ten cocci or more, a plaque is unlikely to be formed and sufficient cocci will survive the initial infection to form a normal lawn of bacterial growth.

The three inhibited staphylococcal strains that were examined showed differences in behaviour which indicated that they were not identical strains. For example, in strain 2, a larger proportion of cocci was able to produce infective phage than did those of the other two strains; lysogenization with phage $009^{\prime}$ increased the average burst size but did not increase significantly the numbers of productive cocci. In strain 676, lysogenization with phage $009^{\prime}$ increased both the numbers of productive cocci and their average yield. On the other hand, lysogenization had no effect on strain 8503.

The effect of lysogenization with phage $009^{\prime}$ on strains 2 and 676 showed that in these staphylococci the ability to synthesize normal amounts of phage was linked with the presence of this prophage which had been derived from a phage-sensitive strain. This effect was not due to prophage substitution such as occurs in staphylococci of phage type $52 / 52 \mathrm{~A}^{\prime} / 80 / 81$ and in which the increased ability to produce phage is retained after the freshly inserted prophage is removed by ultraviolet irradiation. Curing of strain $2\left(009^{\prime}\right)$ of its prophage $009^{\prime}$ infection caused it to revert to incompetence. This indicated that lysogenic conversion was the probable mechanism involved in this change. The genetic constitution of the cocci must also influence the consequences of such lysogenization since strain 8503, although apparently similar to strains 2 and 676 in many of its characters, showed no increased competence to produce phage 47 after lysogenization with phage $009^{\prime}$.

The phenomena described in the present paper differ from those described by West, Kelly \& Shields (1963) who produced inhibitions of normally sensitive staphylococci by altering the salt concentrations in their media and thus altering the adsorption of the phages to their hosts.

This work was supported by a grant from the Australian National Health and Medical Research Council. 

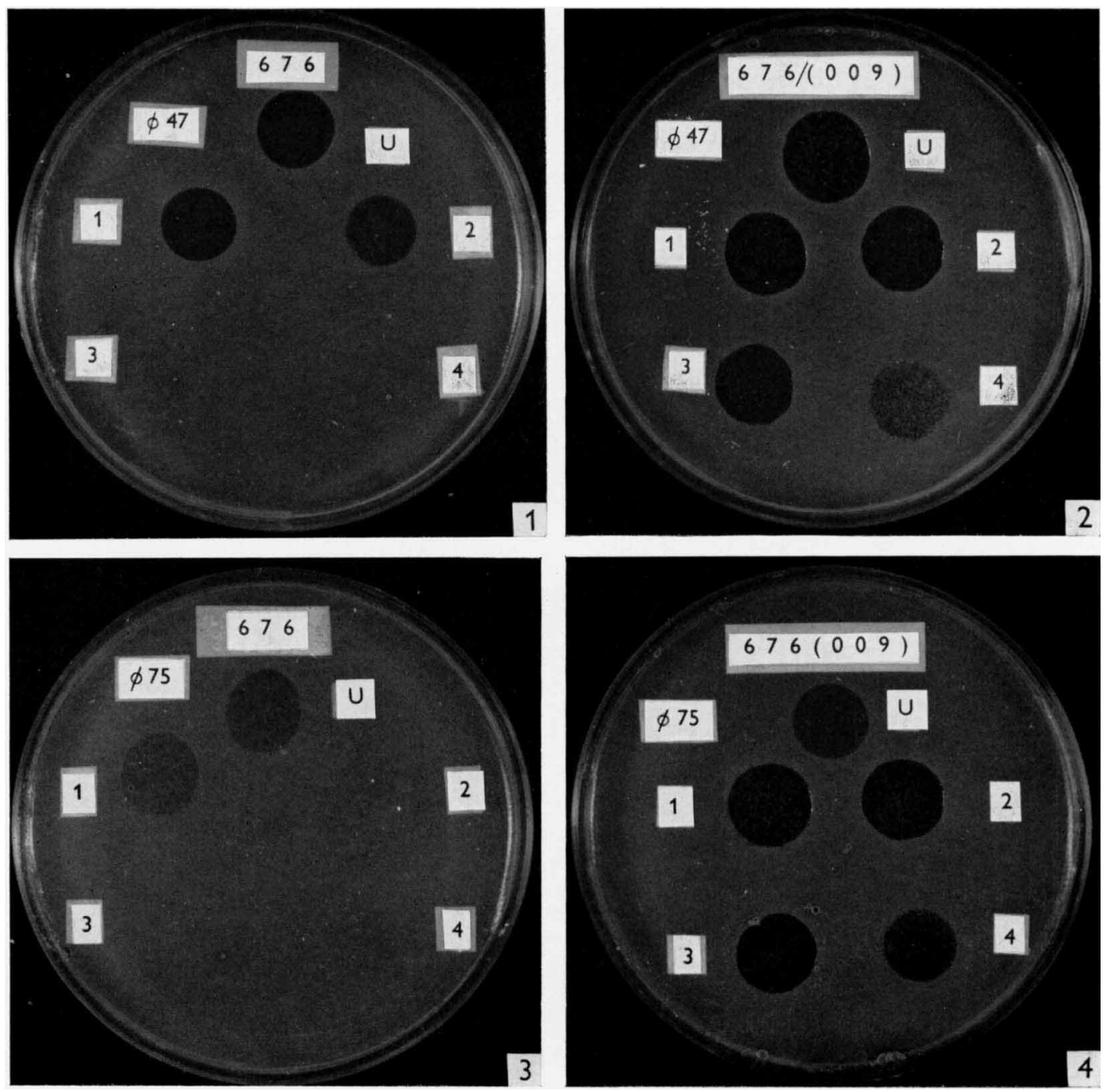


\section{REFERENCES}

Blair, J. E. \& Williams, R. E. O. (1961). Phage typing of staphylococci. Bull. Wld. Hlth. Org. 24, 771.

Monod, J., Cohen-Bazire, G. \& Cohn, M. (1951). Sur la biosynthèse de la $\beta$-galactosidase (lactase) chez Escherichia coli. La specificité de l'induction. Biochim. biophys. Acta, 7, 585.

Rountree, P. M. (1959). Changes in the phage-typing patterns of staphylococci following lysogenization. J. gen. Microbiol. 20, 620.

Rountree, P. M. \& Asheshov, E. H. (1961). Further observations on changes in the phage-typing pattern of phage type 80/81 staphylococci. J. gen. Microbiol. 26, 111.

West, B., Kelly, F. C. \& Shields, D. A. (1963). Effect of sodium chloride on staphylococcus-phage relationships. J. Bact. 86, 773 .

Williams, R. E. O. \& Rippon, J. E. (1952). Bacteriophage typing of Staphylococcus aureus. J. Hyg., Camb. 50, 320.

\section{EXPLANATION OF PLATE}

Titration of phage 47 and phage 75 on Staphylococcus strains 676 and $676\left(009^{\prime}\right)$. Serial tenfold dilutions of phage were deposited on inoculated agar plates; $U=$ undiluted phage; $1=10^{-1}$ dilution; $2=10^{-2}$ dilution; $3=10^{-3}$ dilution; $4=10^{-4}$ dilution.

Figs. 1-2. Titration of phage 47 .

Figs. 3-4. Titration of phage 75 . 